\title{
Resenha do Documento base do exame Celpe-Bras
}

\author{
Mahulikplimi Obed Brice Agossa ${ }^{1}$ \\ Programa de Pós-Graduação em Estudos de Linguagens, Centro Federal de Educação Tecnológica de Minas \\ Gerais, Belo Horizonte, Brasil
}

Resenha da obra:

BRASIL. Instituto Nacional de Estudos e Pesquisas Anísio Teixeira. Documento base do exame Celpe-Bras. Brasília: Instituto Nacional de Estudos e Pesquisas Educacionais Anísio Teixeira, 2020.

Vinte e dois anos após sua primeira aplicação, o exame que confere o Certificado de Proficiência em Língua Portuguesa para Estrangeiros (Celpe-Bras) é dotado de um novo instrumento de referência. Este, no entanto, não é o primeiro ato nesse sentido. Já haviam sido publicados outros documentos, pelos sucessivos órgãos responsáveis pelo exame, que foram editados mais de uma vez. Trata-se de manuais e cartilhas para participantes, com breves explicações sobre o exame, sua estrutura, sua natureza, os níveis de proficiência, dicas de como se preparar, inscrever-se, alguns procedimentos de avaliação etc.; e manuais para avaliadoras e avaliadores, com explicações mais detalhadas sobre o exame, seu construto, os procedimentos de aplicação etc. No entanto, o que o recém-publicado documento base tem de diferente dos demais materiais? Quem são as/os responsáveis pelo conteúdo? Qual a importância do documento para o público usuário do exame?

Uma das possíveis respostas, quanto à particularidade desse documento base, é que ele é a primeira produção oficial, concernente ao exame, que foi registrada com código ISBN e publicada pela editora do próprio Inep. Ademais, além de trazer com muito mais detalhes aspectos abordados nos materiais anteriores, esse documento base, apresenta mudanças aplicadas a diversos elementos constitutivos do Celpe-Bras, acompanhadas das respectivas justificativas, e inova com uma série dos chamados quadros de referência. As/os responsáveis pelo texto são: Edleise Mendes (professora e pesquisadora da Universidade Federal da Bahia, especialista em interculturalidade no ensino de português como língua estrangeira), Juliana R. Schoffen (professora e pesquisadora na Universidade Federal do Rio Grande do Sul, especialista em avaliação), Leandro R. A. Diniz (professor e pesquisador na Universidade Federal de Minas Gerais, especialista em português como língua estrangeira e em políticas

\footnotetext{
${ }^{1}$ Doutorando e bolsista/CAPES no Programa de Pós-Graduação em Estudos de Linguagens/CEFET-MG, Professor de francês no Programa de leitorado de língua francesa e culturas francófonas do CEFET-MG (Extensão). ORCID: http://orcid.org/0000-0003-1752-4719. E-mail: brriceagossa@gmail.com
} 
linguísticas), Matilde V. R. Scaramucci (professora titular e pesquisadora na Universidade Estadual de Campinas, especialista em avaliação de proficiência em português e inglês) e Regina L. P. Dell'Isola (professora titular da Universidade Federal de Minas Gerais, especialista em leitura e produção textual em português como língua materna e língua estrangeira). Tratase de nomes conhecidos nas áreas da Linguística Aplicada ao ensino do português como língua estrangeira (PLE) e da avaliação, nos âmbitos nacional e internacional, devido, entre outros fatores, à sua ampla produção acadêmico-profissional. Além disso, são integrantes da Comissão Técnico-Científica do exame. O documento, com essas características citadas e outras mencionadas ao longo desta resenha, pode representar um marco nas comunidades científicas e docentes do PLE, assim como revelar rumos para mais pesquisas na área da avaliação da proficiência em língua portuguesa.

O material, segundo o Inep, destina-se a participantes do exame, docentes de PLE, pesquisadoras e pesquisadores da área. Objetiva "apresentar o construto do exame e sua operacionalização nas partes escrita e oral". Apesar de se tratar de um documento técnico, a linguagem utilizada não é demasiadamente técnica, o que favorece a leitura por qualquer indivíduo com conhecimentos básicos em linguística. Assim, diferentemente do que afirma o Inep, o material parece inadequado a participantes - em razão de seu volume de informações e pelo fato de já existirem manuais e cartilhas, editados praticamente a cada edição do exame, para esse público - à exceção de quem tenha interesse na avaliação. O documento estruturase em seis capítulos. No final estão anexos atos do Ministério da Educação (portarias de criação, de instituição, de regulamentação do exame e da designação dos órgãos implementadores) e do Inep (portarias de credenciamento de postos aplicadores), bem como versões antigas das grades de avaliação.

No primeiro capítulo, que trata do marco histórico-legal do exame, é relembrada, brevemente, sua história, desde a criação da comissão responsável por sua elaboração, em 1993; passando por sua instituição, em 1994; a aplicação, entre 1998 e 2009, por uma subdivisão da Secretaria de Educação Superior; até a transferência da responsabilidade pelo exame ao Inep, a partir de 2009. Esse capítulo traz, ainda, os objetivos do exame, que são: (i) avaliar a proficiência do público participante em língua portuguesa, supostamente sem discriminação de variantes linguísticas, sejam regionais ou de demais países lusófonos, e (ii) servir como meio para tentar influenciar positivamente o ensino do português no Brasil e fora do país, configurando-se, dessa forma, como um instrumento de política linguística.

O segundo capítulo, que versa sobre o referencial teórico do Celpe-Bras, apresenta a visão comunicativa dentro da qual se inscreve o exame, definindo-se a proficiência em língua portuguesa como construto a ser avaliado, através do uso da língua, operacionalizado por meio de tarefas (não no sentido daquelas utilizadas no Ensino de Línguas Baseado em Tarefas), na Parte Escrita (PE), e de interação face a face, na Parte Oral (PO). O capítulo traz, também, discussões sobre o conceito de proficiência, numa perspectiva de habilidade de usar a língua em diversas situações, adequando-se às demandas pertinentes, demarcando, dessa forma, a visão do Celpe-Bras de outras perspectivas. Ademais, explicita-se a concepção bakhtiniana de gênero discursivo que rege a PE do exame, no sentido de que os enunciados "são produzidos 
em uma situação comunicativa específica, por alguém com um papel específico nessa situação, e são endereçados a interlocutores com propósitos específicos e também produzidos em um contexto, que também produz sentido" (SCHLATTER et al., 2009, p. 105106). A visão de linguagem adotada no exame contempla, também, a indissociabilidade de língua e cultura, considerando a última - mais que um somatório de informações a respeito de um povo e seus hábitos - como um modo de ver a realidade, um elemento que está presente em todas as esferas de atividades de um grupo social e que é, portanto, transparente nos materiais utilizados como insumo no exame.

Outro ponto desse capítulo é a explicitação dos procedimentos de avaliação. Como o exame é de desempenho - isto é, é pedido a cada participante que demostre sua proficiência em português por meio de atividades que representam uma amostra daquilo que precisaria realizar em ambientes de uso da língua -, as situações de avaliação precisam refletir a vida real (o que configura autenticidade), para que as inferências feitas, prevendo a capacidade de sucesso em situações futuras, sejam válidas do ponto de vista do construto. Essa exigência de autenticidade também pressupõe a integração das habilidades (compreensão e produção escritas e orais) da forma mais próxima possível da vida real, afastando-se de atividades tradicionais como leitura de texto para responder a determinadas perguntas, como é possível ver em algumas tarefas das primeiras edições do exame (1998 a 2001/1, por exemplo). Além disso, o Celpe-Bras é demarcado de exames "fatiados" para cada nível de proficiência, justificando-se que situações reais de comunicação não são escolhidas com base em nível de proficiência para a interação, mas que o que diferencia os níveis de proficiência é o desempenho de cada participante na realização das tarefas. Essa última característica, em relação à validade, representa um ponto central.

No terceiro capítulo, são salientados a estrutura do exame e os parâmetros de avaliação das partes escrita ( $P E)$ e oral $(P O)$. No que se relaciona à $P E$, explicitam-se as habilidades envolvidas na realização de cada uma das quatro tarefas - a saber, as compreensões oral, imagética e escrita e a produção escrita. As tarefas são feitas partindo-se de tipos modais de insumos específicos para cada uma delas, sendo um vídeo para a Tarefa 1 , um áudio para a Tarefa 2 (cabe precisar que era o inverso entre essas duas tarefas até a edição de 2004/1) e um texto escrito com/sem imagem para as Tarefas 3 e 4 . Como dito anteriormente, as produções devem observar exigências de gênero discursivo - que contemplam enunciador, interlocutor, propósito(s)/ação(-ões), informações (conteúdo) -, organização textual e recursos linguísticos adequados, porém, não de forma independente da relação de interlocução estabelecida. Para avaliar as produções considerando esses aspectos de gênero, as equipes de avaliação da PE baseiam-se em uma grade holística, apresentada e comentada no documento, com descritores associados a uma escala de 0 a 5 . Destaca-se o fato de essa grade de avaliação ter passado por alterações até 2014, quando entrou em vigor a grade atual. Com efeito, a atual versão da grade define "o ponto de corte entre os níveis avaliados com base na gradação da consistência da interlocução, sem recorrer a descrições da utilização de recursos linguísticos ou da recuperação de informações desvinculadas das condições de recepção e de produção do texto" (p. 41), diferentemente da grade anterior, 
que era semianalítica e se fragmentava em três eixos de avaliação. Essas atualizações foram atribuídas a discussões realizadas durante os eventos de avaliação e a trabalhos acadêmicos. Aliás, pode-se ler em várias ocasiões o verbete "correção", o qual pode carregar uma ideia de feedback e de aprimoramento de produções, diferentemente do termo genérico "avaliação".

Quanto à $\mathrm{PO}$, trata-se de uma interação face a face - entre (e guiada por) um(a) avaliador(a)-interlocutor(a) (AI) e um(a) participante, e acompanhada por um(a) avaliador(a)observador(a) (AO) -, que tem como objetivo examinar o desempenho da/do participante na compreensão e na produção orais. Essa interação "parte de situações de comunicação próximas às reais, procurando simular, na medida do possível, conversas do dia a dia" (p. 41). Ao mesmo tempo que se reconhece a situação de assimetria entre os dois sujeitos que conversam, medidas são recomendadas, no documento, para amenizá-las. Também são ressaltados a estrutura e o conteúdo dessa parte do exame, que dura em torno de 20 minutos, sendo os cinco primeiros minutos reservados a cada participante para que fale mais sobre si, expandindo informações previamente fornecidas por ela/ele, no ato da inscrição. Na sequência da interação, os outros 15 minutos são dedicados a uma interação sobre três temas (pré-)selecionados pela dupla de avaliação, partindo-se dos chamados Elementos Provocadores (EPs), que, normalmente, têm origem nas mídias brasileiras. Para guiar essa interação, a/o Al dispõe de um roteiro que reúne sugestões de perguntas a serem feitas a cada participante. $O$ documento reforça a necessidade de se dinamizar esse roteiro, evitando-se ler as perguntas ipsis verbis. Do mesmo modo estão destacadas as bem-vindas mudanças operadas nesse roteiro, a partir da edição de 2019/2, em que é colocada cópia de cada EP junto ao correspondente roteiro e, também, um campo com breves informações adicionais sobre o tema.

Acerca dos parâmetros de avaliação da PO, o documento traz, e explicita, as dimensões examinadas no desempenho oral de cada participante e que integram, diferentemente da PE, duas grades de avaliação: a grade holística, da qual se utiliza a/o Al e a grade analítica, da qual se utiliza a/o AO. Trata-se de: compreensão oral, competência interacional, fluência, adequação lexical, adequação gramatical e pronúncia. Além disso, são explicados os motivos das últimas mudanças realizadas em ambas as grades. A propósito da nova grade analítica (prevista para ser utilizada a partir de 2020) ${ }^{2}$, foram operacionalizadas três mudanças principais: (i) deixou-se mais claro, no quesito da competência interacional, que quanto maior o nível de proficiência, menor a necessidade de uso de estratégias - com base em pesquisa de Niederauer (2014 apud BRASIL, 2020); (ii) no critério da fluência, houve acréscimo de um descritor para deixar mais claro que uma fala muito lenta, por exemplo, mesmo tendo raras pausas para a resolução de problemas linguísticos, pode comprometer a interação, por ser pouco natural e representar uma forma de monitoramento de possíveis problemas linguísticos; (iii) nos critérios de adequação lexical e de adequação gramatical, houve ajustes para que se tenha em consideração "o impacto da mobilização dos recursos linguísticos na

\footnotetext{
${ }^{2}$ A leitor ou o leitor lerá, na última frase da página 48 , que as grades foram atualizadas para serem utilizadas a partir da segunda edição de 2019, porém, essa informação está desatualizada, posto que as grades utilizadas em 2019/2 são as antigas.
} 
interação, e não a contagem das inadequações linguísticas em si" (p. 53). Já com relação à grade holística (com previsão de implementação em 2020), as mudanças visam "dar mais clareza ao avaliador e padronizar a linguagem em relação à grade analítica, sem alterar os elementos que compõem esses descritores" (p. 54).

O capítulo 4, intitulado "quadros de referência", traz quadros que reúnem especificações detalhadas das duas partes do exame e de seus vários elementos constitutivos, tendo como base a análise das necessidades do público participante, que consiste em "identificar tarefas e papéis [exigidos para o] critério [em foco, no caso, a proficiência] que podem ser utilizados como base para desenhar tarefas em exames de desempenho [...]" (MCNAMARA, 2008, p. 134, tradução ${ }^{3}$ e inserções do autor desta resenha). Sobre a PE, são pormenorizadas, além das habilidades avaliadas em cada tarefa, as características dos textos que servem como insumo: sua modalidade, seu gênero e suas fontes. Ademais, são detalhadas as características discursivas (gêneros, exemplos de relação de interlocução e de propósitos ou ações) e temáticas dos textos solicitados ao público participante. Quanto à PO, são especificados - além das habilidades avaliadas e das mobilizadas - o gênero dos insumos, os propósitos comunicativos e os eixos temáticos avaliados. Em adição a esses quadros, o capítulo encerra-se com mais um quadro, que reúne as especificações da PE e da PO, no que se relaciona aos eixos de avaliação e às sub-habilidades de compreensão e de produção avaliadas. No geral, o papel primário dessas especificações, segundo o documento, é orientar o pessoal de elaboração de itens de avaliação. Cabe destacar que têm também o potencial de auxiliar docentes de PLE a preparar seus alunos e suas alunas de forma mais consciente para o exame.

No capítulo 5 estão descritos os quatro níveis de proficiência certificados no exame: os níveis Intermediário, Intermediário Superior, Avançado e Avançado Superior. Níveis inferiores (o Básico e o Elementar) são avaliados, mas não certificados. Aqui, houve profundas reformulações - implementadas no Edital № 49 do Inep, de 29 de junho de 2020 -, as quais são justificadas no documento. Essas mudanças são visualmente perceptíveis, primeiro, porque os novos descritores gerais (p. 66-67) estão muito mais detalhados e dispostos em dois parágrafos (exceto o nível Intermediário, que pode ter passado despercebido à revisão), sendo o primeiro dedicado às habilidades de produção e de compreensão escritas e o segundo às orais. Além disso, os níveis Intermediário Superior e Avançado Superior são descritos de forma detalhada - diferentemente da versão anterior, em que os pontos de corte entre esses níveis e os respectivos níveis inferiores foram expressos apoiando-se na descrição do imediatamente inferior (o Intermediário Superior, em relação ao Intermediário, por exemplo) e na menor frequência das inadequações.

Outra dimensão importante é que os novos descritores fazem uma diferenciação entre as habilidades de compreender os diversos textos de partida ou insumos (escritos, visuais e orais) e as habilidades de produzir diversos textos sobre assuntos variados (mesmo nos níveis intermediários, diferentemente dos antigos descritores). Em outras palavras, os antigos

\footnotetext{
${ }^{3}$ No original: "Job analysis: The work of identifying tasks and roles in the criterion setting which can be used as the basis for task design in performance tests [...]"
} 
descritores (cf. Anexo G do documento) estabeleciam que a/o participante certificada(o) nos estratos intermediários era quem se mostrava "capaz de compreender e produzir textos orais e escritos [apenas] sobre assuntos limitados, em contextos conhecidos e situações do cotidiano" (p. 131, grifos na fonte, inserção do autor desta resenha). Nos novos descritores, porém, entende-se que as limitações da/do participante dos referidos níveis não estão relacionadas a seu grau de familiaridade com os assuntos, os contextos ou as situações dos textos (escritos ou orais), mas à qualidade dos recursos linguísticos e discursivos empregados para a produção dos diversos textos (escritos e orais). Entretanto, na seção do documento em que está justificada a reformulação dos descritores (item 5.1), são trazidas as especificações dos antigos descritores para referir-se aos novos, no que se relaciona à "produção de textos sobre assuntos variados", nos seguintes termos: "no certificado intermediário, os textos são sobre assuntos limitados, em contextos conhecidos e situações do cotidiano [...]" (p. 66, grifos do autor desta resenha), ocasionando um entendimento contrário ao que aparece nos novos descritores. Ademais, há que se assinalar a remoção, dos novos descritores, das especificações do uso da língua em "contextos conhecidos e situações do cotidiano" e também da tipificação "situações desconhecidas" em relação às possíveis causas de inadequações lexicais e gramaticais.

Outro aspecto desses descritores gerais de proficiência - que, desta vez, não foi justificado no documento, mas merece reflexão - é a manutenção, na descrição de quase todos os níveis (exceto no referente ao Avançado Superior), da distinção entre "estruturas básicas" e "estruturas complexas", que compunha também a grade analítica utilizada até a edição de 2019/2 (cf. Adequação gramatical, notas 0 a 4, p. 127). De fato, esses termos foram retirados da nova grade analítica (critério da adequação gramatical, cf. p. 51), justificando-se a alteração pelo fato de essa distinção ser relativa: "por exemplo, uma estrutura simples para um falante de espanhol pode ser complexa para um falante de inglês, ou vice-versa" (p. 53). Uma das possíveis interpretações dessa ocorrência, por um lado, é que a retirada desses termos pode ajudar na interpretabilidade da grade analítica, deixando-a menos subjetiva. Por outro lado, no entanto, a manutenção dessa distinção entre "estruturas básicas" e "estruturas complexas" nos descritores gerais não parece coerente com o raciocínio utilizado na justificativa da retirada (de dentro da grade analítica). Como essa manutenção não foi justificada, surgem dúvidas quanto às intenções do Inep. Será que a permanência desses termos nos descritores gerais se deve a certa impossibilidade de impactarem a nota final das/dos participantes? Será que esses descritores gerais, que poderão ser utilizados pelos usuários dos resultados do exame (como universidades ou empresas, por exemplo), não continuam com potencial de impactar de alguma forma o público participante? Essas indagações podem ser importantes para a contínua validação do exame.

No último capítulo, são apresentados os procedimentos de avaliação e as técnicas para assegurar a confiabilidade das notas. É explicitada cada etapa, desde a constituição das equipes de avaliação dedicadas a cada tarefa da PE e à reavaliação das interações face a face cujas notas tenham discrepado de forma significativa, até a atribuição da nota final correspondente ao nível de proficiência de cada participante. São salientados, ainda, o perfil 
acadêmico/profissional das avaliadoras e dos avaliadores, que precisam ser da área das Letras, e a capacitação presencial (p. 71) dada às equipes de (re)avaliação para discussão e alinhamento das grades. Tanto para a PE quanto para a PO, são feitos treinamentos de avaliação de alguns textos e áudios pré-selecionados pela coordenação de cada equipe de avaliação (dentre amostras estratificadas) e, então, é dado, início à avaliação propriamente dita. O material destaca, ainda, o fato de todas as produções escritas e todos os áudios serem (re)avaliados por pares aleatórios, de forma independente, com o intuito de aumentar-se a confiabilidade dos resultados. Dessa forma, quando há discrepância significativa entre as notas atribuídas por qualquer par a determinada produção, essa é reavaliada - no caso da PE, por uma terceira pessoa da equipe de avaliação e, no caso da PO, por mais um par, sempre com as duas grades da PO. Tratando-se, ainda, da PO, em caso de mais uma discordância significativa, será feita uma segunda reavaliação - mantendo-se o uso das duas grades, diferentemente das edições anteriores a 2020, em que a segunda reavaliação de determinada interação era realizada por uma só pessoa, que utilizava a grade holística. Outro procedimento adotado, para monitorar e aprimorar a fidedignidade dos resultados, é a avaliação (no caso da $\mathrm{PE}$ ) e a reavaliação (no caso da $\mathrm{PO}$ ) de algumas produções pré-selecionadas pelo conjunto de integrantes de cada equipe.

Após a resolução das discrepâncias significativas (incluindo-se aí casos em que a nota da PE seja maior que a da PO em 2,0 pontos ou mais), quando há, a nota atribuída a cada participante define seu nível de proficiência, numa escala de 0 a 5 , sendo que para obter a certificação, é preciso atingir, tanto na Parte Escrita quanto na Parte Oral, uma nota igual ou superior a 2. A nota final é a menor das atribuídas em cada uma das partes a cada participante. O porquê dessa escolha (da menor nota), no entanto, não está explicitado. Cabe ressaltar que todo esse complexo processo de (re)avaliações é representado de forma visual em dois fluxogramas - sendo um para a PE e outro para a PO - proporcionando condições para fácil entendimento.

Apresentados esses seis capítulos em que se divide o documento base, um aspecto do exame que também merece uma reflexão, é a exigência do Celpe-Bras a nacionais dos Países Africanos de Língua Oficial Portuguesa (PALOP), a partir de 2013, mediante o Decreto Presidencial no 7.948, de 12 de março daquele ano, que regula o Programa de EstudantesConvênio de Graduação (PEC-G). Ademais, convém lembrar que, a partir do mesmo ano desse Decreto exclusivo ao PEC-G, passou-se a exigir de estudantes dos PALOP comprovação de proficiência em português para o Programa de Estudantes-Convênio de Pós-Graduação (PECPG) - seja por meio do Celpe-Bras ou de comprovação provisória assinada por Instituição de Ensino Superior brasileira -, com a condição de apresentarem, no prazo de dois anos após o início do curso, a aprovação no Celpe-Bras. ${ }^{4}$ Desde seu início, no entanto, o exame foi desenvolvido para avaliar a proficiência em português como língua estrangeira.

4 Editais e Manuais do PEC-PG disponíveis em: http://www.capes.gov.br/bolsas-e-auxiliosinternacionais/pais/218-multinacional/9651-programa-de-estudantes-convenio-de-pos-graduacao-pec-pg Acesso em: 30 jul. 2020. 
Levando-se em consideração tudo o que foi abordado no documento base, cabe afirmar que seu objetivo - o de apresentar o construto do exame e sua operacionalização foi cumprido com sucesso e que certamente haverá pesquisas relevantes partindo das bases lançadas. E, como admitido na obra aqui resenhada, é primordial que os aspectos que compõem o Celpe-Bras continuem sendo alvos de estudos - a exemplo daqueles que têm impactado de alguma forma aspectos do exame e que foram mencionados no próprio documento -, para que se aprimorem cada vez mais a validade do instrumento e a fidedignidade dos resultados.

\section{Referências}

BRASIL. Instituto Nacional de Estudos e Pesquisas Anísio Teixeira. Documento base do exame Celpe-Bras. Brasília: Instituto Nacional de Estudos e Pesquisas Educacionais Anísio Teixeira, 2020. Disponível em: http://portal.inep.gov.br/informacao-da-publicacao/Lasset publisher/6JYIsGMAMkW1/document/id/6939071. Acesso em: 05 dez. 2020.

MCNAMARA, T. Language Testing. 10. ed. Oxford: Oxford University Press, 2008.

SCHLATTER, M. et al. Celpe-bras e Celu: impactos da construção de parâmetros comuns de avaliação de proficiência em português e em espanhol. In: ZOPPI-FONTANA, M. G. $O$ português do Brasil como língua transnacional. Campinas: RG, 2009. p. 95-122.

Recebido em: 02/08/2020.

Aceito em: 01/12/2020. 